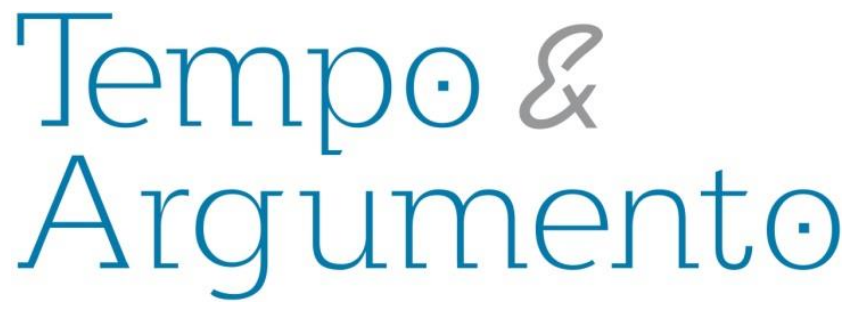

\title{
O museu está morto. Viva o museu!
}

\section{Janice Gonçalves}

Doutora em História Social pela

Universidade de São Paulo (USP).

Docente do Departamento de História e do

Programa de Pós-Graduação em História da

Universidade do Estado de Santa Catarina (UDESC).

Florianópolis - SC - Brasil

janice.gnclvs@gmail.com

\author{
Para citar este texto: \\ GONÇALVES, Janice. O museu está morto. Viva o museu! [Debate]. Revista Tempo e \\ Argumento, Florianópolis, v. 10, n. 25, p. 515 - 522, jul./set. 2018. \\ DOI: $10.5965 / 2175180310252018515$ \\ http://dx.doi.org/10.5965/2175180310252018515
}

No livro Os espólios de Poynton, publicado em 1897, o escritor estadunidense Henry James estrutura sua narrativa ficcional em torno de uma coleção de objetos de arte que foram reunidos minuciosa e demoradamente pelo casal Gereth. Como nos romances de Jane Austen, a história tem entre seus temas a difícil situação das mulheres inglesas no momento da transmissão de uma herança. Na trama, a Sra. Gereth, já viúva, preocupada com o destino que seu filho (único herdeiro) poderia dar à coleção - que a rigor já era 
dele -, anima-se com a perspectiva de ter encontrado uma jovem sensível às qualidades e ao valor dos objetos por ela reunidos; caso viesse a se tornar sua nora, juntas poderiam selar uma aliança que resultasse não somente na preservação dos objetos como na manutenção do acesso privilegiado da colecionadora a eles. Todavia, nada transcorrerá como desejava a Sra. Gereth, que deixará de residir em Poynton (a propriedade em que sua adorada coleção estava abrigada). Pior: a residência e, por consequência, os objetos preciosos que continha viriam a ser consumidos em um grande incêndio, provavelmente causado por um descuido banal - "alguma chaminé enferrujada ou algum daqueles lampiões portáteis largado no lugar errado" (JAMES, 2008, p. 217).

Perdas de grandes coleções devidas a incêndios, acidentais ou não, fizeram parte do enredo de outras obras literárias - como não lembrar, por exemplo, do sucesso editorial dos anos 1980, O Nome da Rosa, no qual a preciosa e afamada biblioteca da abadia medieval onde transcorrem os acontecimentos é transformada em cinzas? (ECO, 1983) Ou como não referir a distopia de Ray Bradbury, Fahrenheit 451, livro lançado em 1953 que apresenta uma sociedade na qual os livros são proibidos e os bombeiros são incumbidos de eliminá-los com fogo? É da boca do personagem Beatty que Bradbury faz brotar a seguinte fala:

O que é o fogo? É um mistério. Os cientistas nos oferecem jargões pomposos sobre fricção e moléculas. Mas realmente não sabem. Sua verdadeira beleza é que ele destrói a responsabilidade e as consequências. Se um problema se torna um estorvo pesado demais, para a fornalha com ele. (BRADBURY, 2007, p. 141)

Dosado, o fogo está associado ao poder transformador da cultura, como no mito clássico de Prometeu; extremado, pode voltar-se contra os próprios bens culturais, de forma incontornável.

Para além das expressões literárias, a destruição pelo fogo pontua a história concreta de numerosos locais que abrigaram acervos expressivos, em diferentes momentos históricos. Como destacou Matthew Battles, referindo-se especificamente a bibliotecas e, sobretudo, a ações intencionais, "a queima de livros não é uma invenção recente. Ela espreita a história das bibliotecas, de Alexandria a Tenochtitlán, da Capadócia 
à Catalunha, da dinastia chinesa de Qin à dissolução dos mosteiros na Inglaterra." (BATTLES, 2003, p. 157) No "breve século XX", como proposto por Eric Hobsbawm (1995), a "era da guerra total" gerou cenários de destruição que, além de bibliotecas, atingiram duramente museus, arquivos e centros de documentação. Os grandes conflitos armados do século XXI, seja guerras entre nações ou guerras civis, não têm sido menos catastróficos, a este respeito.

Se realizada de forma deliberada, a destruição costuma estar a serviço de projetos de dominação; o lado que destrói busca afirmar simbolicamente sua superioridade, ainda que circunstancial, fundando um novo tempo no qual tentam ser rompidos, pela eliminação de vestígios materiais, os vínculos dos derrotados com o passado. Mas é preciso lembrar que o exercício da dominação pode se dar igualmente pelo reverso da destruição: em tais casos, os bens culturais tidos como valiosos são preservados, porém apropriados como signos da vitória e da superioridade do vitorioso. Nessa clave, Walter Benjamin, durante a Segunda Guerra Mundial, no dramático ano de 1940, considerou, em uma de suas teses sobre o conceito de História, que os bens culturais estão indelevelmente marcados pela barbárie, sendo o butim que os dominadores se aprazem em exibir:

Todos os que até hoje venceram participam do cortejo triunfal, em que os dominadores de hoje espezinham os corpos dos que estão prostrados no chão. Os despojos são carregados no cortejo, como de praxe. Esses despojos são o que chamamos bens culturais. (BENJAMIN, 1985, p. 225)

As coleções dos museus históricos nacionais nasceram com aquela terrível marca, pois foram constituídas, via de regra, em articulação com os butins decorrentes de conquistas promovidas pelos países imperialistas no século XIX, o que é atestado por parte significativa dos acervos que compõem museus como o Britânico e o do Louvre. Em museus como esses, a afirmação da história da nação foi combinada de forma sui generis com a história "universal”:

[...] a História Nacional representaria a culminação do desenvolvimento da civilização. Daí a importância dos museus de arqueologia das civilizações clássicas da Grécia e de Roma, bem como do Egito e da Mesopotâmia. (MENESES, 1994, p. 15) 
O vínculo almejado com o universal, mesmo que em uma perspectiva mais antropológica do que histórica, esteve presente na constituição do Museu Nacional, na Quinta da Boa Vista, Rio de Janeiro - incendiado de forma devastadora na noite de 2 de setembro de 2018. Sendo um museu vinculado à Universidade Federal do Rio de Janeiro (UFRJ), seu incêndio abalou profundamente pesquisadores, funcionários e usuários mais frequentes, além de comover e surpreender negativamente pessoas em todo o país e fora dele, especialmente aquelas ligadas ao campo do patrimônio cultural.

O Museu Nacional brasileiro se configurou e consolidou na linha dos museus de história natural. Surgido antes da independência (a criação ocorreu em 1818), com a denominação de Museu Real, deveria, conforme o decreto de criação, servir à propagação dos "conhecimentos e estudos das Ciências naturais do Reino do Brasil, que encerra em si milhares de objetos dignos de observação e exame" (apud CHAGAS, 2006, p. 39). Daí a presença de coleções de paleontologia, zoologia, geologia, botânica, arqueologia e antropologia biológica; somaram-se a elas, ainda, as coleções etnográficas. Seu acervo também incorporou, em alguma medida, a perspectiva de integração entre história nacional e história "universal”, como denotam aquisições feitas por membros da família imperial, nas primeiras décadas de existência da instituição (vale mencionar a coleção de artefatos egípcios da Antiguidade, bem como os artefatos advindos de escavações realizadas em Pompéia e Herculano - MUSEU NACIONAL, 2018). A maior aproximação ao perfil científico de seus congêneres europeus teria se dado apenas a partir dos anos 1870 - antes disso, o museu seria repositório de "coleções e curiosidades, expostas sem qualquer classificação" (SCHWARTZ, 1993, p. 71). Até o início da década de 1890, o Museu Nacional esteve instalado no Campo de Santana, só então passando a ocupar a Quinta da Boa Vista. O vínculo direto com a universidade, estabelecido a partir dos anos 1940, favoreceu a renovação na composição e no estudo de suas numerosas e significativas coleções, alimentando perspectivas críticas abertas a uma leitura a contrapelo de seu acervo; simultaneamente, nesse processo, seu tratamento e sua difusão ganharam em complexidade. 
Assim como a memória mantém uma relação dialética com o esquecimento, a preservação dos bens culturais entendidos como patrimônio alimenta-se da relação com a destruição - se não completamente evitada, ao menos adiada ou mitigada, pois tudo o que existe no tempo está sujeito à degradação. O sentido da finitude dos seres e das coisas torna a empreitada de preservação necessariamente desafiadora. Mas a notável capacidade destrutiva do incêndio do Museu Nacional, que devorou seu principal edifício - o Paço ou Palácio de São Cristóvão, tombado em nível federal - pôs a descoberto fragilidades que não dizem respeito apenas à condição de submissão dos elementos materiais à ação transformadora e debilitadora do tempo. Afinal, não se trata da única instituição custodiadora de acervo que, no Brasil, sofreu a ação do fogo, resultando em perdas irreparáveis (em especial se considerada a presença de itens únicos em suas coleções ou arquivos). Entre os casos mais recentes, cabe citar o incêndio do Museu da Língua Portuguesa, em 2015, e o da Cinemateca Brasileira, em 2016, ambos na cidade de São Paulo. São indícios de problemas estruturais que dizem respeito ao menos à manutenção das edificações e aos recursos humanos e financeiros disponíveis.

O antropólogo José Reginaldo Santos Gonçalves, ao refletir sobre sociedades não ocidentais em que os procedimentos de produção social de memória também incluem positivamente a destruição de elementos materiais, ressaltou:

Caberia ao pesquisador, para entender de modo mais sistemático o campo dos patrimônios e dos museus, dedicar tanta atenção às práticas de preservação quanto ao seu avesso, as práticas de destruição, as quais acompanham as primeiras como uma sombra. (GONÇALVES, 2015, p. 225)

Atentos ao alerta do autor, caberia ainda pensarmos que, se ações premeditadas de destruição, parcial ou total, com frequência incidem sobre os bens culturais (mesmo aqueles formalmente reconhecidos como de interesse para preservação), é certo que há outras formas mais sutis de destruir. A catástrofe no Museu Nacional foi temerariamente ajustada ao desenho de novas condições políticas para as ações de preservação do patrimônio cultural brasileiro, como indicam duas medidas provisórias editadas cerca de uma semana depois do incêndio do Museu Nacional. 
A primeira (MP n. 850, de 10/09/2018) autoriza o poder Executivo a criar, em substituição ao Instituto Brasileiro de Museus (IBRAM), a Agência Brasileira de Museus (ABRAM), "na forma de pessoa jurídica de direito privado sem fins lucrativos"; no Art. 20, $\S 3^{\circ}$ dessa MP, prevê-se que os bens do IBRAM, incluídos aqueles de 27 unidades museais, “poderão ser destinados à ABRAM, a critério do Ministério da Cultura, mediante cessão de uso ou cessão do direito real de uso". Dado seu vínculo com a UFRJ, o Museu Nacional não foi incluído entre essas unidades museais, mas convém salientar que a edição da medida provisória foi precedida de propostas de retirada do museu da alçada da universidade. A segunda medida provisória (MP n. 851, de 10/09/2018) dispõe sobre a constituição de fundos patrimoniais que possam ser voltados, entre outras esferas, à cultura, à educação e à ciência, além de instituir o "Programa de Fomento à Pesquisa, ao Desenvolvimento e à Inovação - Programa de Excelência". Para gerir os fundos patrimoniais, a MP prevê, em seu Art. $2^{\circ}$, uma “organização gestora de fundo patrimonial”, definida como “instituição privada, sem fins lucrativos, instituída na forma de associação ou fundação privada, para atuar exclusivamente para um fundo na captação e na gestão das doações oriundas de pessoas físicas e jurídicas e do patrimônio constituído".

Em setembro de 2018 vivenciamos a morte do Museu Nacional - ao menos, daquele Museu Nacional que, não obstante as inúmeras mudanças nos rumos de sua trajetória, em dois séculos, remontava suas origens a um projeto iniciado sob Dom João VI. O rescaldo do incêndio ainda não é de todo conhecido, e uma pequena parte do caudaloso acervo do museu (estimado em 20 milhões de itens) sobreviveu ou está em processo de recuperação, como dão conta as notícias que aos poucos vêm sendo veiculadas ${ }^{1}$. Mas tudo indica que o Museu Nacional, tal como era conhecido, não poderá ser reativado. Por outro lado, inspirando-nos nas reflexões de Henry Rousso, a partir de comentários de Hermann Heimpel (ROUSSO, 2016, p. 24-27), talvez possamos pensar a hipótese de que a catástrofe na Quinta da Boa Vista fundou o tempo presente do Museu

\footnotetext{
${ }^{1}$ Até o momento, a mais destacada pela grande imprensa é aquela que dá conta da localização, em outubro, de fragmentos do mais antigo fóssil humano encontrado em território brasileiro - "Luzia". Haverá agora o esforço de reconstituição. O sítio eletrônico do Museu Nacional (www.museunacional.ufrj.br) tem concentrado notícias similares na aba "Resgate pós-incêndio".
} 
Nacional, lançando, àqueles que buscam reconstruí-lo sobre as bases da pesquisa científica, desafios profundamente novos e imprevistos. Que das cinzas, como no mito grego, possa ser promovido seu renascimento em meio à noite densa. Viva o museu, vivam os museus, viva o patrimônio cultural brasileiro!

\section{Referencias}

BATTLES, Matthew. A conturbada história das bibliotecas. São Paulo: Editora Planeta do Brasil, 2003.

BENJAMIN, Walter. Sobre o conceito da história. In: BENJAMIN, Walte. Obras escolhidas - v. 1: Magia e técnica, arte e política. São Paulo: Brasiliense, 1985. p. 222-232.

BRADBURY, Ray. Fahrenheit 451. São Paulo: Globo, 2007.

BRASIL. Presidência da República. Medida provisória n. 850, de 10 de setembro de 2018. Disponível em: <http://www.planalto.gov.br/CCIVIL_03/_Ato20152018/2018/Mpv/mpv850.htm>. Acesso em: 13/10/2018.

BRASIL. Presidência da República. Medida provisória n. 851, de 10 de setembro de 2018. Disponível em: <http://www.imprensanacional.gov.br/materia/lasset_publisher/KujrwoTZC2Mb/content/id/40360904/do1-2018-09-11-medida-provisorian-851-de-10-de-setembro-de-2018-40360808>. Acesso em: 13/10/2018.

CHAGAS, Mário. Há uma gota de sangue em cada museu: a ótica museológica de Mário de Andrade. Chapecó: Argos; CEOM, 2006.

ECO, Umberto. O Nome da Rosa. Rio de Janeiro: Nova Fronteira, 1983.

GONÇALVES, José Reginaldo Santos. O mal-estar no patrimônio: identidade, tempo e destruição. Estudos Históricos, Rio de Janeiro, v. 28, n. 55, p. 211-228, 2015.

HOBSBAWM, Eric J. Era dos extremos: o breve século XX, 1914-1991. São Paulo: Companhia das Letras, 1995. 
JAMES, Henry. Os espólios de Poynton. São Paulo: Companhia das Letras, 2008.

MENESES, Ulpiano Toledo Bezerra de. Do teatro da memória ao laboratório da História: a exposição museológica e o conhecimento histórico. Anais do Museu Paulista, São Paulo, v. 2 (N. Ser.), p. 9-42, 1994.

MUSEU NACIONAL. O Museu. [2018]. Disponível em: <www.museunacional.ufrj.br>. Acesso em 22 out. 2018.

ROUSSO, Henry. A última catástrofe: a história, o presente, o contemporâneo. Rio de Janeiro: FGV Editora, 2016.

SCHWARTZ, Lilia Moritz. O espetáculo das raças: cientistas, instituições e questão racial no Brasil, 1870-1930. São Paulo: Companhia das Letras, 1993.

Universidade do Estado de Santa Catarina - UDESC

Programa de Pós-Graduação em História - PPGH

Revista Tempo e Argumento Volume 10 - Número 25 - Ano 2018 tempoeargumento@gmail.com 